\title{
Direct Metal Laser Sintering of Ti6Al4V for Biomedical Applications: Microstructure, Corrosion Properties, and Mechanical Treatment of Implants
}

\author{
Janette Brezinová ${ }^{1}$, Radovan Hudák ${ }^{2}$, Anna Guzanová ${ }^{1, *}$, Dagmar Draganovská ${ }^{1}$, \\ Gabriela Ižaríková ${ }^{3}$ and Juraj Koncz ${ }^{1}$ \\ 1 Department of Mechanical Technology and Materials, Technical University of Košice, Mäsiarska 74, \\ Košice 04001, Slovakia; janette.brezinova@tuke.sk (J.B.); dagmar.draganovska@tuke.sk (D.D.); \\ juraj.koncz@tuke.sk (J.K.) \\ 2 Department of Biomedical Engineering and Measurement, Technical University of Košice, Letná 9, \\ Košice 04001, Slovakia; radovan.hudak@tuke.sk \\ 3 Department of Applied Mathematics and Informatics, Technical University of Košice, Letná 9 , \\ Košice 04001, Slovakia; gabriela.izarikova@tuke.sk \\ * Correspondence: anna.guzanova@tuke.sk; Tel.: +421-55-602-3515
}

Academic Editor: Hugo F. Lopez

Received: 30 May 2016; Accepted: 7 July 2016; Published: 20 July 2016

\begin{abstract}
Ti6Al4V samples have been prepared by Direct Metal Laser Sintering (DMLS) with varied laser power. Some of the samples were stress-relief annealed. The microstructure of materials was investigated using a light microscopy. Columnar grains of martensite dominate in as-made microstructure. Stress-relief annealing led to the white acicular phase growth in the structure with a fishbone arrangement on the boundary of some original martensitic needles. Mechanical properties of materials were characterized through hardness measurement in two directions relating to the sample building direction. It was found that the hardness of materials increased with a laser power and values varied from 370 to $415 \mathrm{HV}$ 0.3/30. After stress-relief annealing, the structure of materials being homogenized, pattern spacing dissolved and the hardness in both directions became stabilized at values of 350-370 HV 0.3/30. The laser power affects the corrosion rate of the material. The lowest corrosion rate was recorded at the maximum laser power $(190 \mathrm{~W})$. Heat treatment does not affect the corrosion rate remarkably, however it leads to stabilization of corrosion potential of materials Ecorr. The surface of the samples was modified by an abrasive blasting using spherical (zirblast) and sharp-edged (white corundum) blasting abrasives and three levels of air pressure. The abrasive blasting of sintered materials led to a decrease of the surface roughness of materials with air pressure increasing. Blasting with zirblast led to a more significant decrease of roughness parameters compared with surfaces blasted with sharp-edged white aluminum. Different shapes of abrasives caused characteristic surface morphology.
\end{abstract}

Keywords: Ti6Al4V; DMLS (Direct Metal Laser Sintering); corrosion rate; microstructure; abrasive blasting

\section{Introduction}

In the field of applied biocompatible materials in medicine, there is continuous development [1-4]. The materials used for biomedical applications must exhibit certain specific characteristics, namely sufficient mechanical properties, corrosion resistance [5,6], and biocompatibility. For production reasons, their workability is also a matter of concern.

Titanium and Ti-based alloys are considered to be the most attractive metal materials for biomedical purposes and form a huge part of materials used in the construction of dental and 
orthopedic implants, as well as facial and plastic surgery [7]. The strong point is its excellent biocompatibility. It has no allergic or sensitizing effect, and moreover is not carcinogenic or toxic. A layer of titanium oxide even gives bacteriostatic effect. Other beneficial properties of titanium alloys are their low electrical conductivity, high corrosion resistance, predictable thermodynamics, and good strength-to-weight ratio. Titanium has the ability to self-passivate in most corrosive environments, although it belongs to the non-noble metals with high negative potential $(-1633 \mathrm{mV})$. The thickness of $\mathrm{TiO}_{2}$ passivation layer varies between 20 and $50 \mathrm{~nm}$, it protects the material against corrosion and ensures its bio-inertness. The advantage of this passivation layer is the self-restoration if broken e.g., during the machining of the material. Titanium passes either to the active state, namely in reducing environments with low $\mathrm{pH}$, or in environments where soluble titanium complexes are formed. Hydride layer $\mathrm{TiH}_{2}$ is formed under conditions with hydrogen depolarization. The layer has the same passivation ability at the small concentrations of non-oxidizing acids. The formation of a hydride or oxide layer is also linked with changes of titanium electrode potentials.

The resistance of titanium against certain substances can be increased either by changing the composition of the Ti alloy, surface treatment of the Ti alloy in various ways [8], or by change in composition of a corrosive environment. The corrosive environment in biomedical applications is given by conditions in the intrabody environment, the change is not possible. The significant improvement of mechanical properties of Ti alloys can be achieved by alloying elements such as aluminum, vanadium, palladium, zirconium, chromium, and copper, however these components may not be tolerated by a human body environment [9]. Another possibility of influencing the resistance of titanium alloys is a surface treatment, especially anodic oxidation. Utilizing suitable voltage can increase the resistance of titanium against some acids at elevated temperatures. Annealing also allows the increase of corrosion resistance of titanium alloys by forming a continuous surface layer of oxides. Another possibility is modifying the surface morphology of implants mechanically—abrasive blasting. Blasting enables to change the morphology of surfaces to roughen or smooth out according to individual requirements [10-12]. Abrasive blasting lead to changes in a surface area size and roughness parameters, the removal of both the surface layers and the subsurface work hardening occur together with changes of mechanical properties and surface activity.

Blasting parameters influencing the quality of the surface, according to [13]:

- material and grain size of blasting abrasive,

- distance between the surface and blasting nozzle,

- abrasive impact angle,

- abrasive velocity,

- $\quad$ intensity of blasting (given by applied abrasive mass per area or by blasting time).

The technology and parameters of the production of the implants are also involved in the final properties, Figure 1. Influence of particular DMLS parameters on the final implant properties was investigated by many researchers [14-20]. Manufacturing of fitted implants are often implemented by a rapid prototyping (RP) technology, since each product possesses the unique shape. RP technologies are an additive technology using CAD models that transforms into thin horizontal layers and then shapes particular material to the final product. In DMLS (Direct Metal Laser Sintering) technology, remelting of powder with a laser beam occurs [21,22].

The aim of this paper is to determine the impact of the laser power in Ti6Al4V powder sintering on the microstructure, mechanical properties, and corrosion resistance of the final product. The opportunity to modify the surface morphology of implants by an abrasive blasting with two blasting abrasives is verified as well. 


\section{Process Parameters}

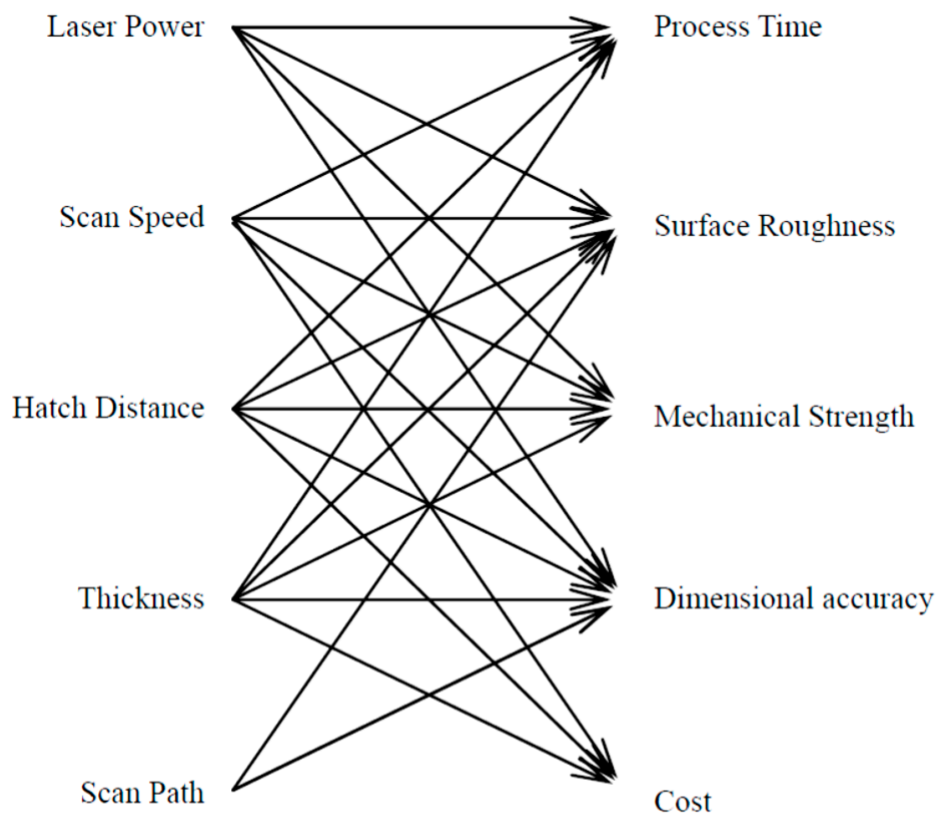

\section{Resulting Properties}

Cost

Figure 1. The influence of sintering parameters on final properties of material in DMLS technology [23].

\section{Materials and Methods}

For the realization of experimental work, a powder of Ti6Al4V alloy has been used, Table 1 . This commercial powder had spherical morphology with an average particle size of $50 \mu \mathrm{m}$. Test samples were prepared by DMLS technology using EOSINT M280 (nominal power $200 \mathrm{~W}$, EOS Electro Optical Systems, Munich, Germany), Figure 2.

Table 1. Chemical composition of powder used (wt. \%).

\begin{tabular}{cccccccc}
\hline Al & $\mathbf{V}$ & $\mathbf{F e}$ & $\mathbf{O}$ & $\mathbf{N}$ & $\mathbf{H}$ & $\mathbf{C}$ & Ti \\
\hline $5.75-6.75$ & $3.5-4.5$ & max. 0.25 & max. 0.20 & max. 0.05 & max. 0.015 & max. 0.08 & balance \\
\hline
\end{tabular}

In DMLS technology the powder is provided to the working cylinder in a thin layer of a fixed thickness. Simultaneously, the powder surface in the working cylinder is scanned with a high-energy $\mathrm{Yb}$-fiber laser system according a defined pattern. The scanner has a significant impact on the part accuracy. It guides the laser beam arriving from the beam expander optics along a defined path over the building area using two mirrors operated by galvanometers. An integrated autocalibration feature (home-in function) checks the mirror positions and regulates the positions if necessary. In this way offset drift and gain drift are significantly reduced. The laser beam is focused on the building area using an F-Theta objective.

The layer sintering process is repeated till the whole part is created. The powder is locally melted at the laser beam track and then solidified. A steel platform serves as structural support and heat dissipation during sintering. To protect from oxidation, the process takes place in an argon atmosphere. 


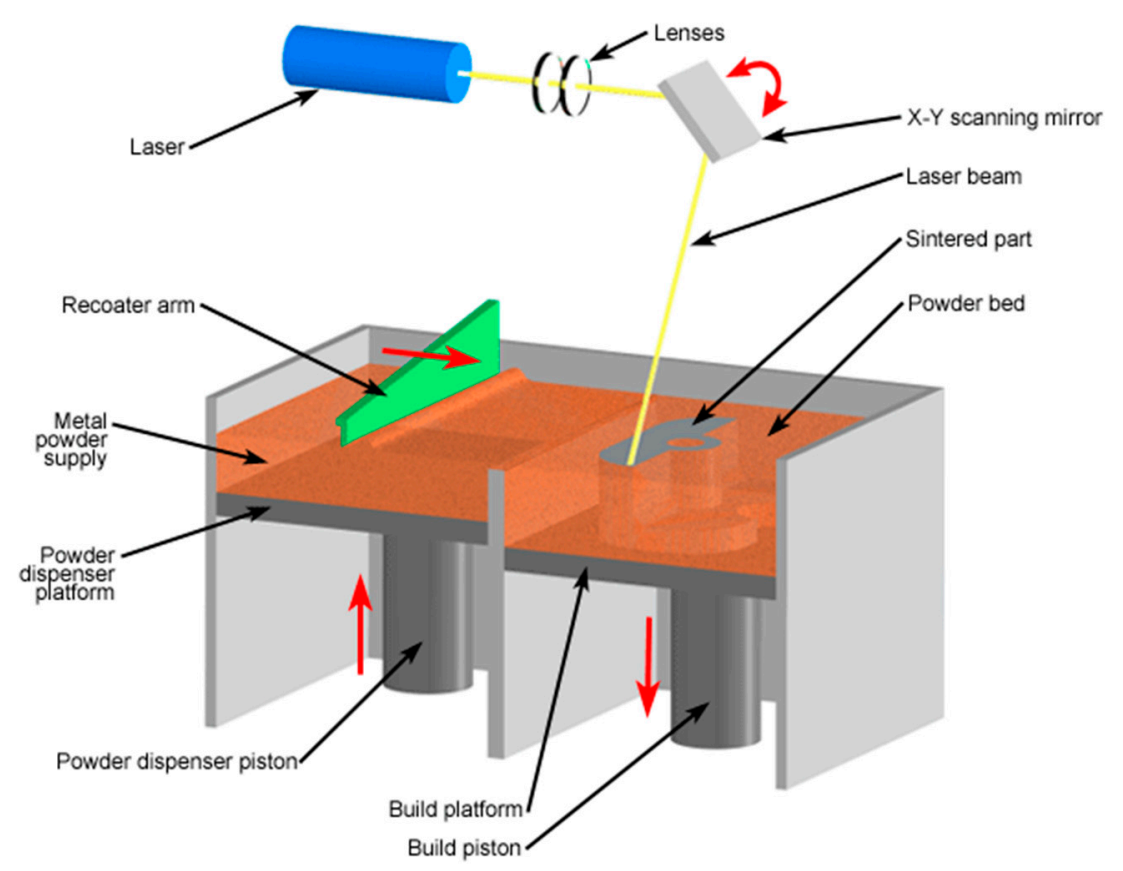

Figure 2. Scheme of DMLS technology [24].

\subsection{The Shape and Dimensions of the Test Samples}

For experimental works, three groups of test samples with dimensions of $20 \mathrm{~mm} \times 20 \mathrm{~mm} \times 2 \mathrm{~mm}$ were performed. These groups differ in the power of laser sintering: $150 \mathrm{~W}, 170 \mathrm{~W}, 190 \mathrm{~W}$. Laser speed was $1250 \mathrm{mmps}$, wavelength of Yb-fibre laser beam: 1060-1100 nm, wavelength of the pumping beam: 960-980 nm, the thickness of the layer was $0.03 \mathrm{~mm}$. Variable focus diameter (the spot size) was adjusted to $0.1 \mathrm{~mm}$. Focal length of the F-Theta objective: $410 \mathrm{~mm}$, divergence (solid angle): approx. 20-30 mrad. Stepover $0.1 \mathrm{~mm}$.

\subsection{Heat Treatment of Materials}

The half of the test samples were heat treated after sintering-stress-relief annealing. Annealing temperature was $850^{\circ} \mathrm{C}$, dwell time $2 \mathrm{~h}$, argon atmosphere. Heat treatment (anealing) was used to release mechanical stress accumulated during direct metal laser sintering (DMLS) process and modify the mechanical properties (high strength and ductility).

Heat treatment is done by placing the part in a carrier flooded with argon at room temperature and afterwards placing the carrier in the preheated oven. Standard laboratory ovens control the inner chamber temperature, which is different from the surface and inner part temperature. To control the part temperature, a sensor placed on the part or better in a drill hole inside of the part should be used. For all parts the dimensions must be taken into account and the holding time needs to be adjusted to assure everything is thoroughly heated through (greater than $2 \mathrm{~min} / \mathrm{mm}$ thickness but at least $30 \mathrm{~min}$ ).

\subsection{Metallographic Study of Materials}

The metallographic analysis of sintered materials was performed in two directions-perpendicular and parallel to deposited layers, Figure 3.

The metallographic samples were ground on a set of abrasive papers, polished using polishing silica suspension and etched using Kroll's reagent, 5-10 s at $25^{\circ} \mathrm{C}$. The evaluation of materials microstructure was observed by the light microscopy (Olympus BXFM, Hamburg, Germany). 


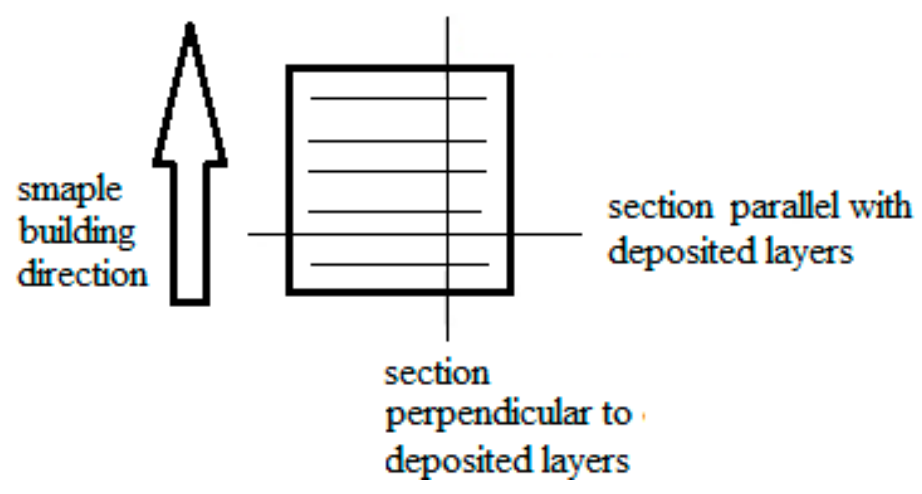

Figure 3. Way of material collection for metallographic observation.

\subsection{Hardness of Materials}

The effect of change of the laser power on the structure and mechanical properties of sintered materials was determined by measuring the microhardness on metallographic sections. The hardness measurement was performed on hardness tester Shimadzu HMV2 (Shimadzu, Tokio, Japan), with a load of $2.942 \mathrm{~N}$ and a dwell time of $30 \mathrm{~s}$ (HV 0.3/30).

\subsection{Corrosion Properties of Sintered Materials}

Measurement of corrosion properties of materials was carried out by potentiodynamic test using potentiostat SP 150 (Bio-Logic Science Instruments, Claix, France) and the results were analyzed by EC Lab software (version V10, Bio-Logic Science Instruments, Claix, France). A three electrode system was implemented: working electrode—-test sample, reference electrode—saturated calomel electrode (SCE), and a platinum auxilliary electrode, Figure 4 . To simulate the intrabody environment, measurements were realized in $3.5 \% \mathrm{NaCl}$ solution (physiological solution).

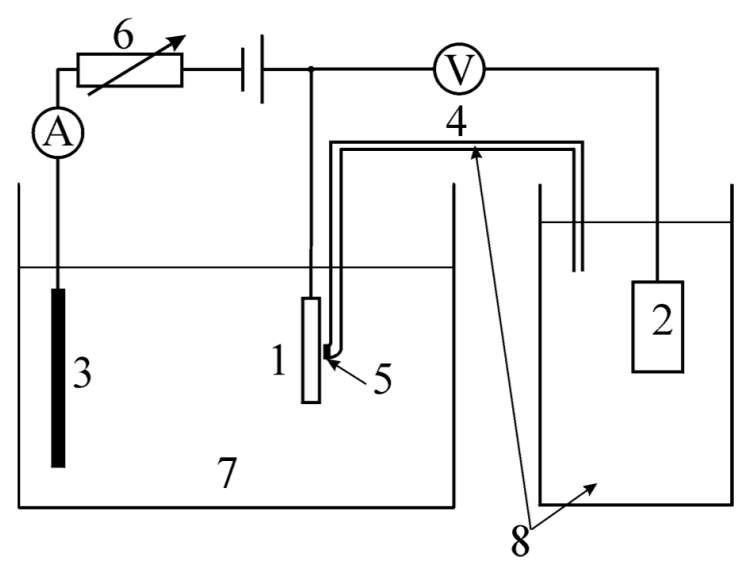

Figure 4. Three electrode system: 1-working electrode; 2-reference electrode; 3-auxiliary electrode; 4-salt bridge; 5-semipermeable membrane; 6-adjustable voltage source; 7-electrolyte; 8—solution of own ions of reference electrode.

An equivalent circuit, consisting of capacitor and resistance connected in parallel, was utilized, Figure 5.

The time of sample stabilization in the electrolyte was $30 \mathrm{~min}$ with recording of free potential every five seconds, or when the minimum potential change $\pm 5 \mathrm{mV}$ occurred. Forced polarization was within the range from $-0.3 \mathrm{~V}$ against the free potential to $1 \mathrm{~V}$ against a reference SCE potential. The polarization rate was $1 \mathrm{mV} \cdot \mathrm{s}^{-1}$. The resulting current density depending on the inserted potential was plotted in semi-logarithmic coordinates and analyzed by Tafel analysis. 


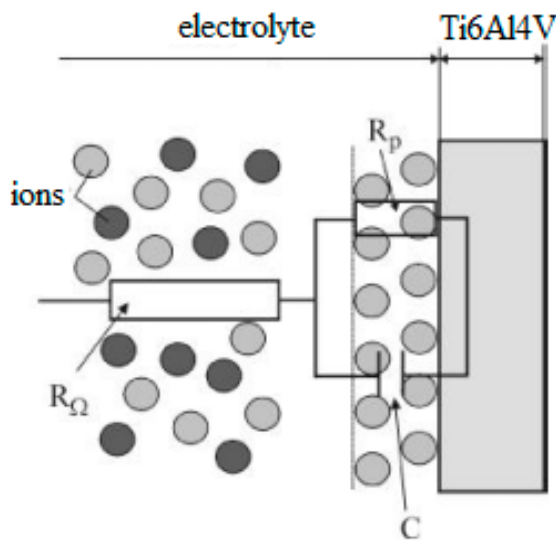

Figure 5. Interpretation of equivalent circuit for a simple corrosion system.

\subsection{Modification of Surface Morphology of Sintered Materials}

Two blasting abrasives for modification of the surface morphology of sintered materials were utilized-Zirblast B60 and white corundum FEPA 120. Zirblast is the ceramic abrasive, characterized by a greater density and effectivity than glass abrasives and less density than steel abrasives. It is used for surface hardening or cleaning molds etc. White corundum is an abrasive based on synthetic aluminum oxide intended for blasting in closed systems. It is a high resistance abrasive to achieve high quality of the treated surface. Chemical composition of the abrasives is presented in Table 2 and physical properties in Table 3.

Table 2. Chemical composition of abrasives in wt. \%.

\begin{tabular}{ccccccccc}
\hline Abrasive & $\mathrm{Al}_{2} \mathrm{O}_{3}$ & $\mathrm{ZrO}_{2}$ & $\mathrm{SiO}_{2}$ & $\mathrm{Fe}_{2} \mathrm{O}_{3}$ & $\mathrm{TiO}_{2}$ & $\mathrm{CaO}$ & $\mathrm{Na}_{2} \mathrm{O}$ & Others \\
\hline Zirblast & - & 67 & 30 & - & - & - & - & $<3$ \\
White corundum & $>99.6$ & - & $<0.03$ & $<0.04$ & $<0.01$ & $<0.01$ & $<0.20$ & $<0.2$ \\
\hline
\end{tabular}

Table 3. Physical properties of abrasives.

\begin{tabular}{ccc}
\hline Property & Zirblast & White Corundum \\
\hline Grain size & $0.125-0.250 \mathrm{~mm}$ & $0.09-0.125 \mathrm{~mm}$ \\
Shape/Colour & spherical/white & Sharp-edged $/$ white \\
Hardness & $8 \mathrm{Mohs}$ & $9 \mathrm{Mohs}$ \\
Density & $3.85 \mathrm{~kg} \cdot \mathrm{dm}^{-3}$ & $3.9 \mathrm{~kg} \cdot \mathrm{dm}^{-3}$ \\
\hline
\end{tabular}

A pneumatic air-blast device Sandblasting System TM 0.5 (Rösler, Prescot, UK) was utilized-Miniblast 200. The samples were blasted with abrasives at working pressures of $0.2,0.4$, and $0.6 \mathrm{MPa}$, nozzle diameter was $1.2 \mathrm{~mm}$, blasting angle $75^{\circ}$, and the distance of the nozzle from the substrate was $200 \mathrm{~mm}$. The samples were blasted until full surface coverage was achieved. Some roughness parameters in 2D and surface volume in 3D were subsequently measured.

2D evaluation was carried out in accordance with STN EN ISO 4287 using Surftest SJ-201 (Mitutoyo, Kanagawa, Japan). Measured parameters were as follows: Ra (an arithmetical mean deviation of the profile on the sampling length), $R z$ (the maximum height of profile on the sampling length), Rt (the total height of profile on the evaluation length), RSm (mean width of the profile elements on the sampling length) and a non-normalized parameter RPc which defines peak count (the number of roughness profile peaks per an unit length).

$3 \mathrm{D}$ visualization of surfaces was realized by putting together particular parallel surface profiles received from a stylus profilometer with spacing of $0.1 \mathrm{~mm}$. The $3 \mathrm{D}$ reconstruction of the surfaces was carried using MATLAB. The size of visualized area was $4 \mathrm{~mm} \times 4 \mathrm{~mm}$. 
Settings in roughness measurement:

- $\quad$ measured profile: $R$

- filter: GAUSS

- $\quad$ sampling length $1(\lambda c): 0.8 \mathrm{~mm}$

- number of sampling lengths: $n=5$

- $\quad$ evaluation length $l n: 4 \mathrm{~mm}$

- number of measured profiles: 40.

Using MATLAB software, a surface volume of blasted samples was also evaluated. The surface volume $(V p)$ is a type of volume relating to a unit of nominal surface area. It is the free space between a plane passing through the highest peak and a real surface of the base material. This parameter is used as an example for assessing of tribological nodes, where we can determine an estimated consumption of lubricants and, in the case of biological implants, surface volume affects acceptance of the implant by the human body.

\subsection{Statistical Evaluation of Surface Morphology of Sintered Materials}

The effect of pressure on the value of individual roughness parameters and an influence of blasting media on the parameters for samples blasted by a white corundum and Zirblast were evaluated by ANOVA. We have observed whether the pressure has an effect on the value of the parameter, i.e., statistically significant or insignificant difference. The hypothesis that was tested as the null hypothesis (H0: mean values are the same). The second hypothesis is called an alternative hypothesis, denoted by H1. The significance level $\alpha$ ( $\alpha$-type I error) is the probability of rejection of the null hypothesis although it is true $(\alpha=0.05, \alpha=0.01)$. $p$-value is the lowest level of significance at which the null hypothesis can be rejected. If $p<\alpha$ the null hypothesis is relevant to the alternative hypothesis is rejected. This means that the difference measured in the sample is too large to be merely incidental. Between those variables is a relationship. If $p \geqslant \alpha$ null hypothesis cannot be rejected, it means that the difference measured in the sample can be merely incidental.

It is applied:

- $\quad p<0.05$ "statistically significant difference"

- $\quad p<0.01$ "highly statistically significant difference"

- $\quad p>0.05$ "statistically significant difference".

\section{Results}

Microstructures of the materials sintered using different laser powers are shown in Figures 6 and 7.

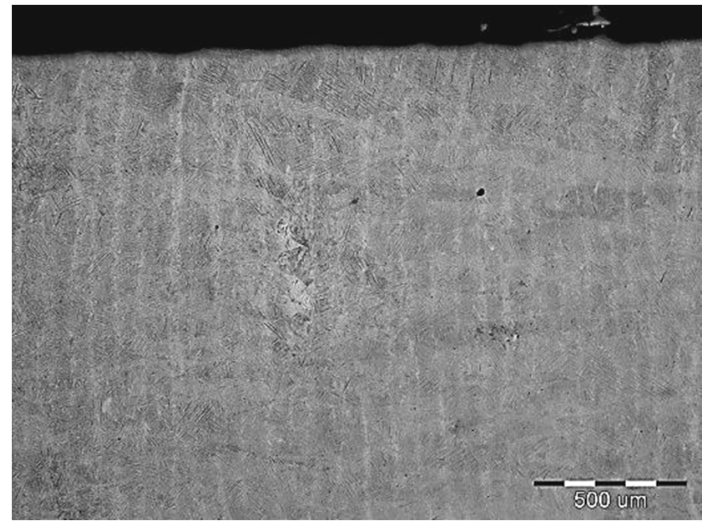

$150 \mathrm{~W}$

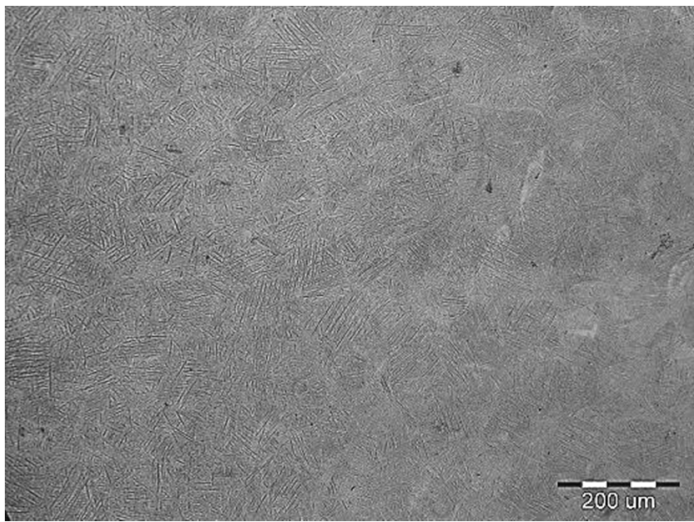

$150 \mathrm{~W}$

Figure 6. Cont. 


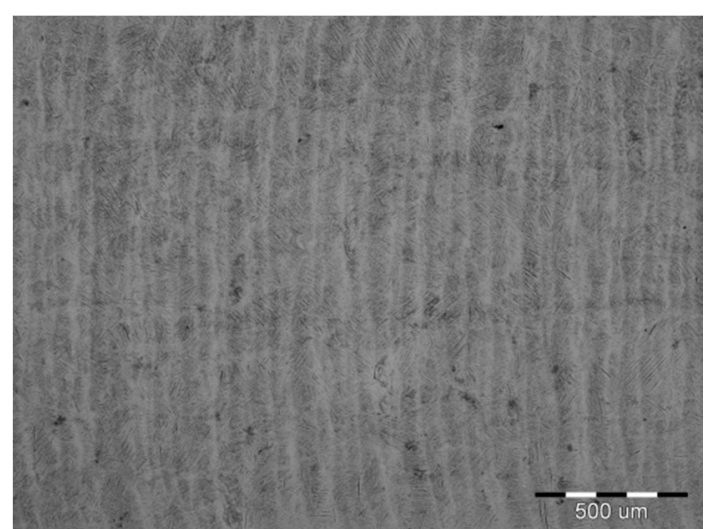

$170 \mathrm{~W}$

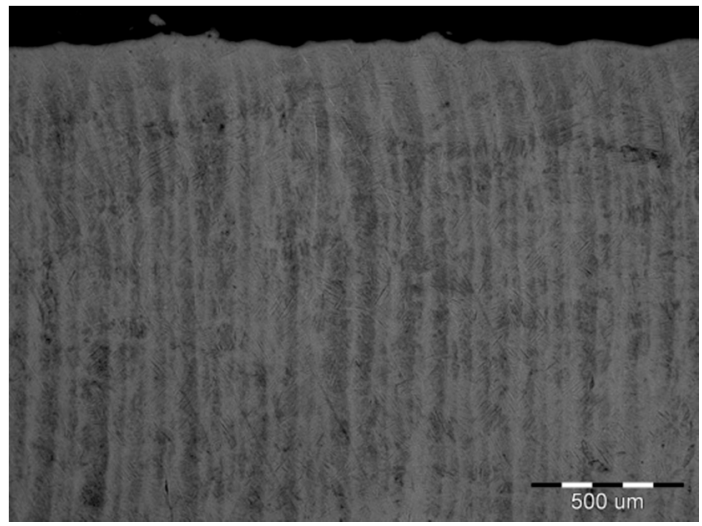

$190 \mathrm{~W}$

perpendicular to deposited layers

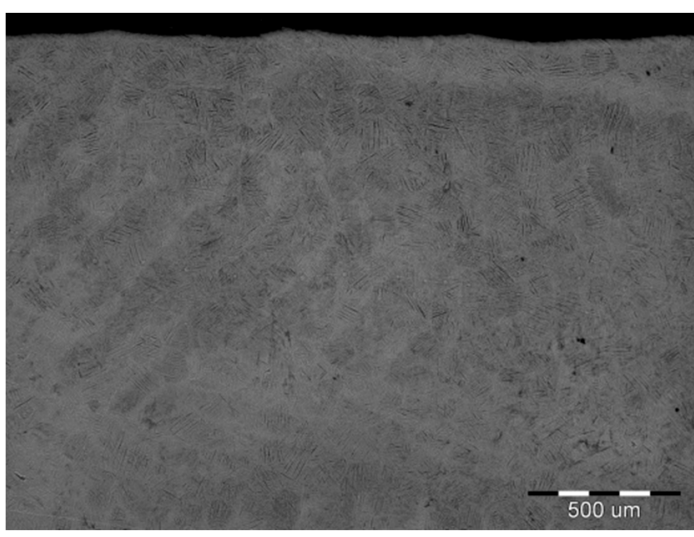

$170 \mathrm{~W}$

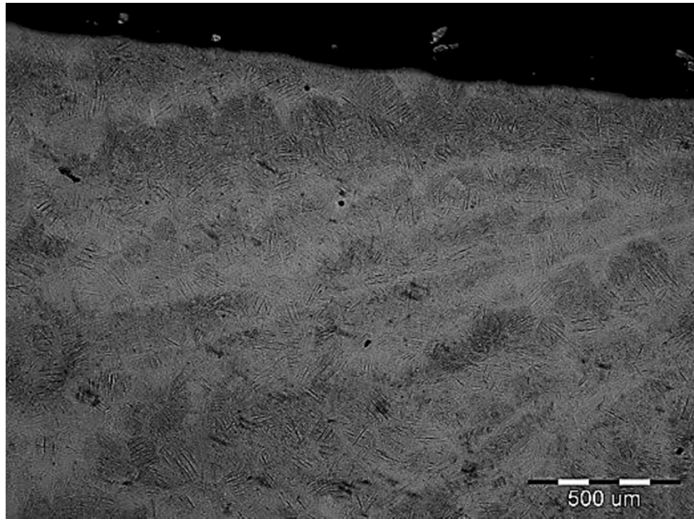

$190 \mathrm{~W}$

parallel with deposited layers

Figure 6. Microstructure of sintered materials, $50 \times$ mag., LM.

At low magnification (Figure 6), a pattern relating to sintering particular powder layers in section perpendicular to the layers deposition can be observed. The pattern appears to be columnar grains orientated to the direction of build. The microstructure of the sintered material at a magnification of $500 \times$ are shown in Figure 7.

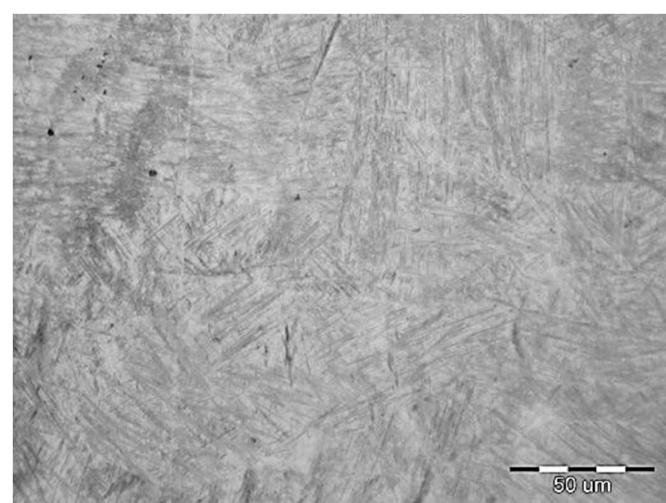

$150 \mathrm{~W}$

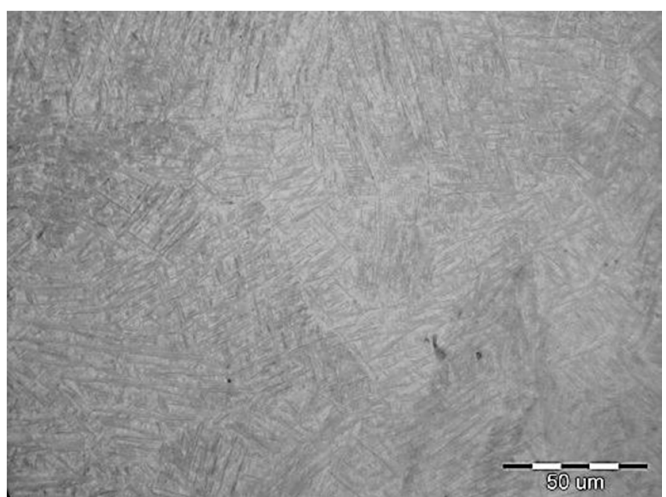

$150 \mathrm{~W}$

Figure 7. Cont. 


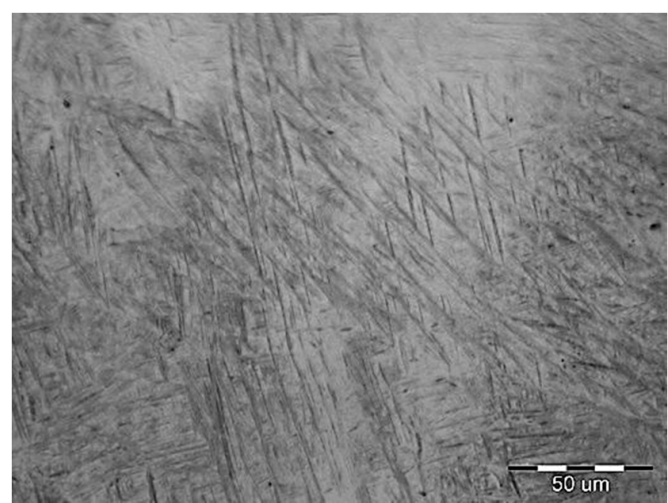

$170 \mathrm{~W}$

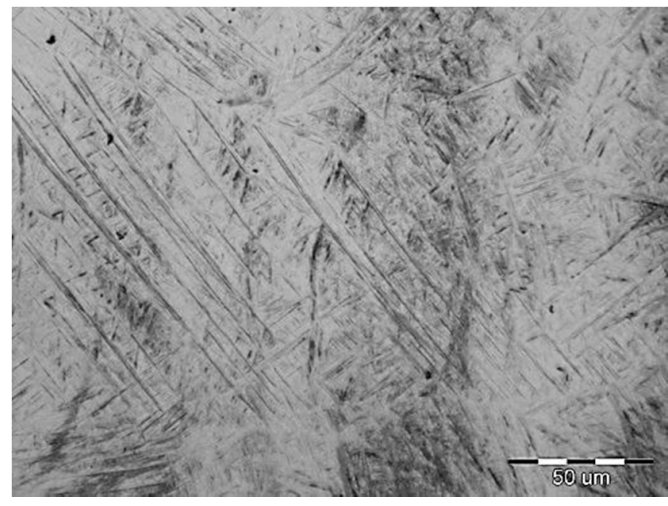

$190 \mathrm{~W}$

perpendicular to deposited layers

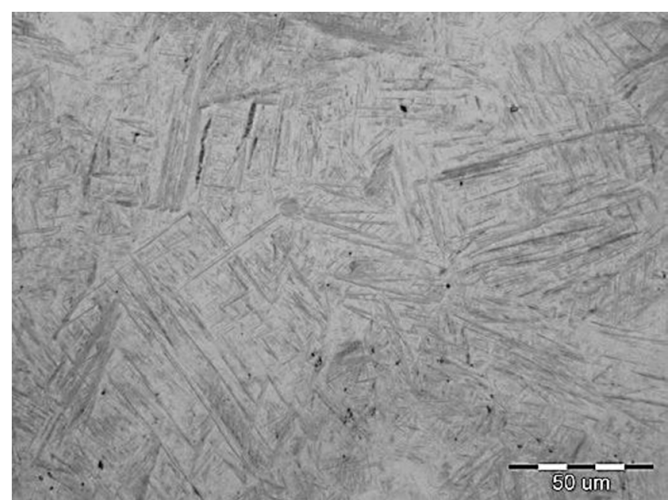

$170 \mathrm{~W}$

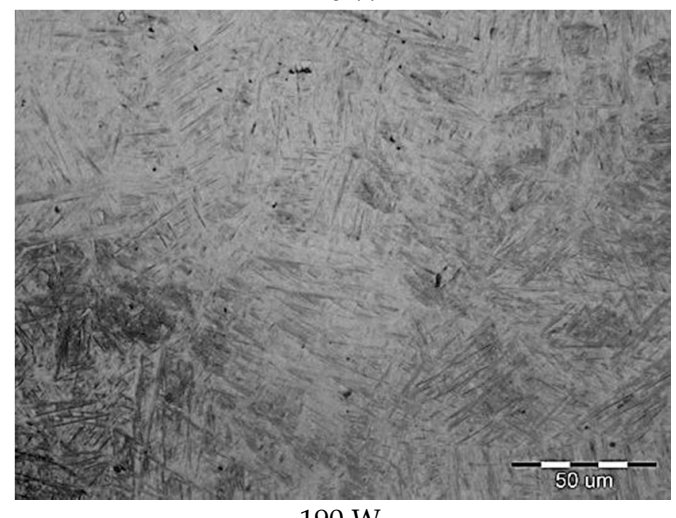

$190 \mathrm{~W}$

parallel with deposited layers

Figure 7. Microstructure of sintered materials, mag. 500×, LM.

Microstructure of materials after stress-relief annealing are shown in Figure 8.

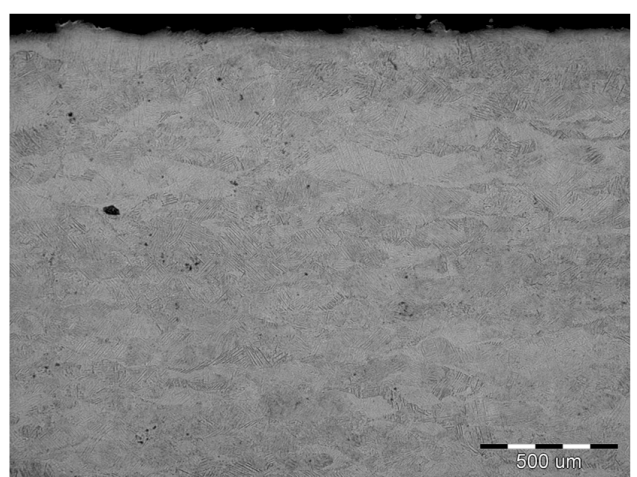

$150 \mathrm{~W}$

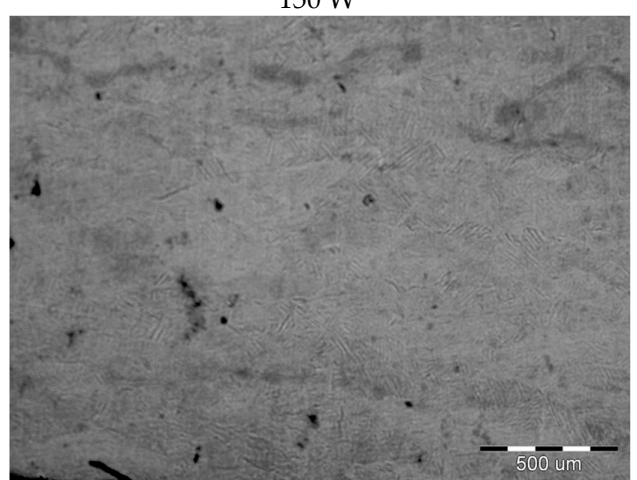

$170 \mathrm{~W}$

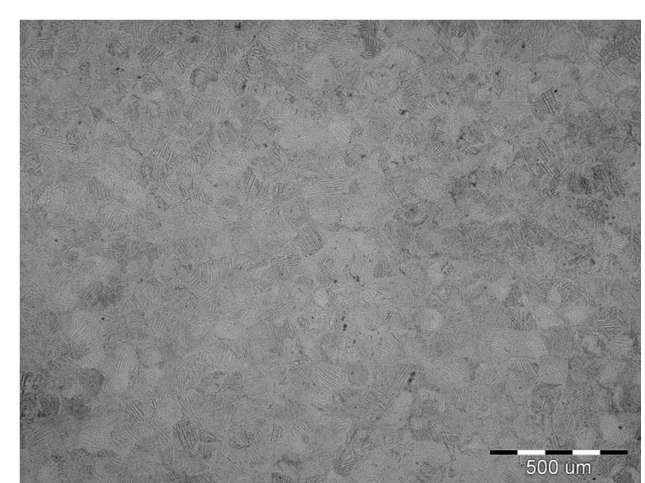

$150 \mathrm{~W}$

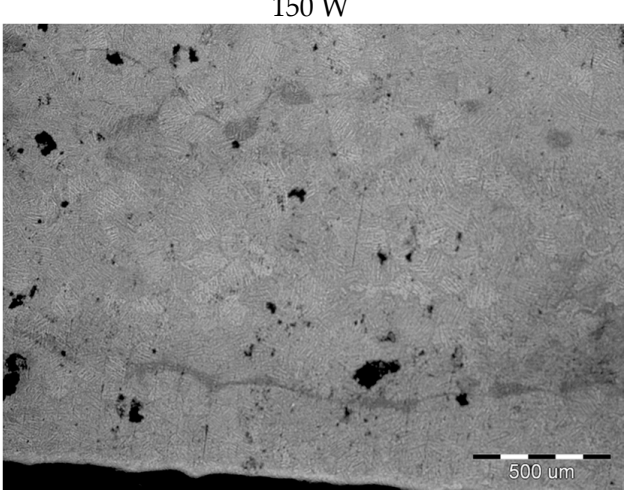

$170 \mathrm{~W}$

Figure 8. Cont. 


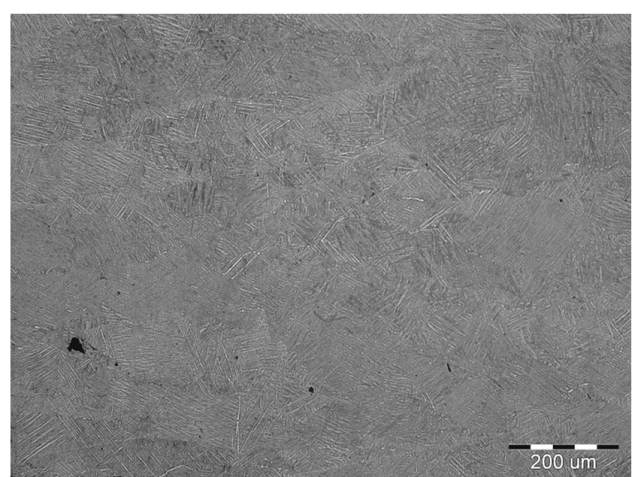

$190 \mathrm{~W}$

perpendicular to deposited layers

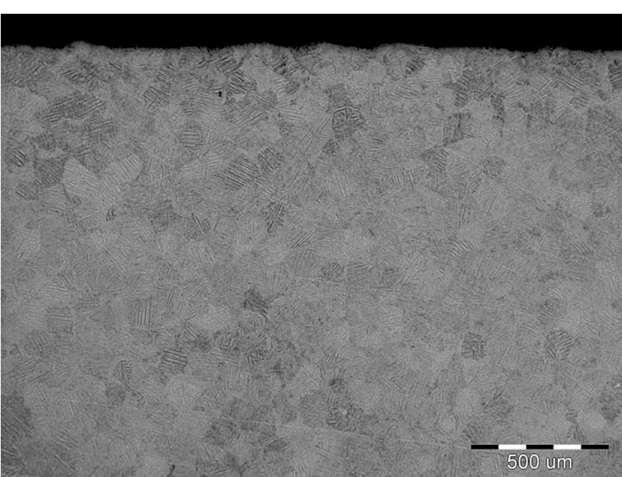

$190 \mathrm{~W}$

parallel with deposited layers

Figure 8. Microstructure of annealed materials, mag. 500×, LM.

From metallographic analysis we can conclude:

- $\quad$ annealing leads to structure pattern dissolving

- due to the fact that the analyzed alloy is of $(\alpha+\beta)$-type, the primary structure after sintering is lamellar, it has a fine morphology consisting of primary $\alpha$ phase and the acicular phase of probably $\alpha^{\prime}$-phase martensite, the rest of structure consists of $\beta$ phase

- $\quad$ in all analyzed materials, after annealing occurs, there is white acicular phase in the structure with a fishbone arrangement, the phase appears on the boundary of some original martensitic needles, although a significant amount of original martensite needles remain unchanged after annealin

- $\quad$ since annealing was realized below $\alpha \rightarrow \beta$ transition temperature, growth $\beta$ of the phase has not been recorded

- $\quad$ the structure in metallographic sections parallel with deposited layers before and after annealing is equiaxed polyhedric, without visible porosity, high density, and integrity of the material

- $\quad$ microstructures do not show any significant differences with respect to different laser powers

The hardness of sintered materials depending on the laser power measured in two directions is shown in Figure 9.

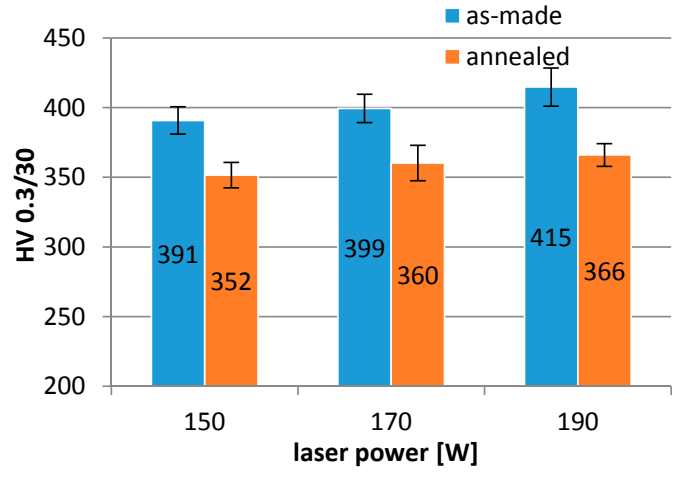

(a)

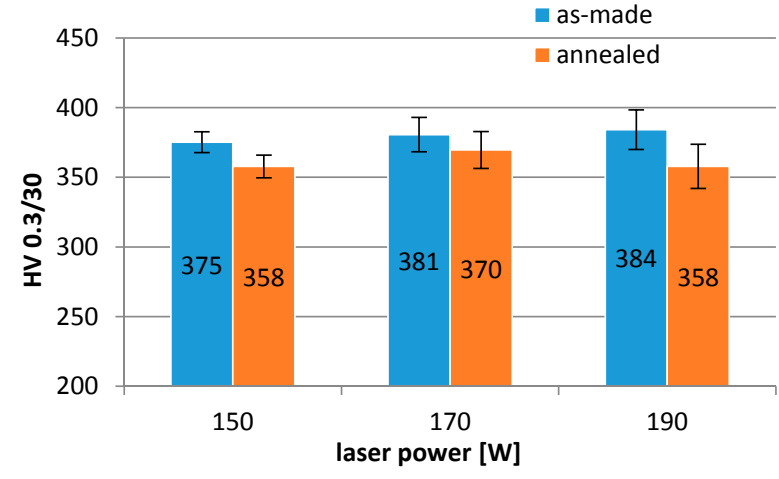

(b)

Figure 9. Hardness of materials depending on the laser power and the direction. (a) Perpendicular to deposited layers; (b) parallel with deposited layers.

The measured results showed the increase of laser power led to an increase in hardness of materials in both measuring directions. In the direction perpendicular to deposited layers there was recorded higher hardness than in parallel direction. After annealing, the hardness of materials for 
all laser powers and both measuring directions decreased. More remarkable decrease of materials hardness was recorded in perpendicular direction compared to parallel direction. This fact can due to dissolving of structure pattern and material structure homogenization.

Corrosion rate of materials after $144 \mathrm{~h}$ exposure in the test solution, depending on the laser power and heat treatment, is provided in Figure 10.

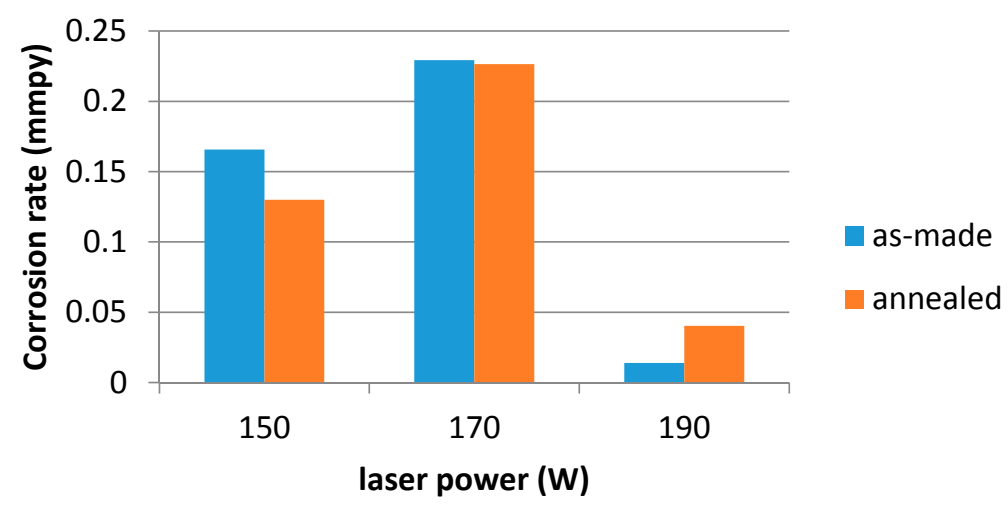

Figure 10. Corrosion rate after $144 \mathrm{~h}$ exposure in the test solution.

Figure 10 indicates that the laser power effects the corrosion rate of the material. The lowest corrosion rate was recorded at maximum laser power $(190 \mathrm{~W})$. Heat treatment does not effect the corrosion rate remarkably, however it leads to stabilization of corrosion potential of materials Ecorr, Figure 11.

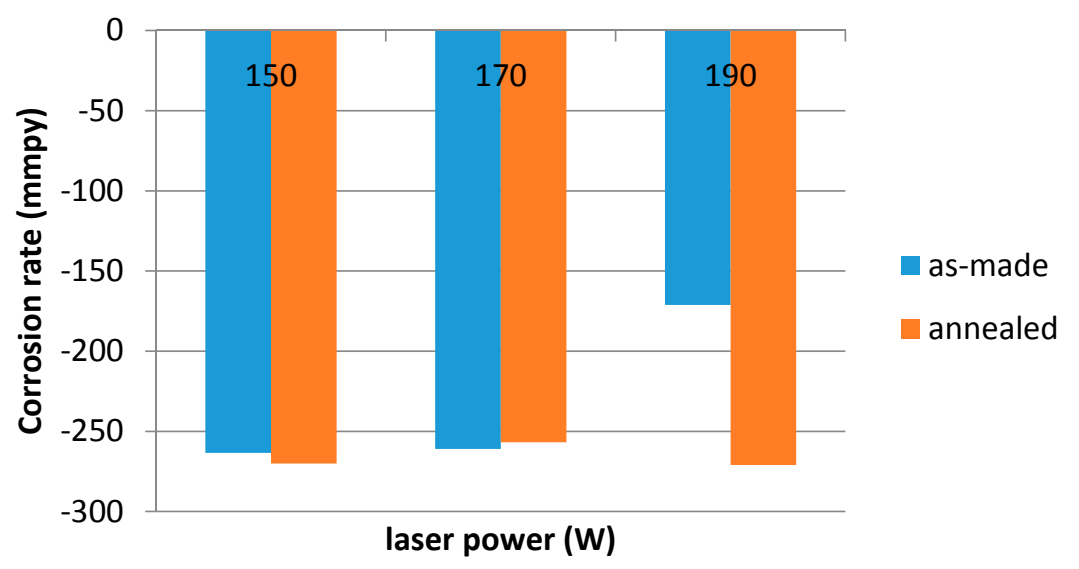

Figure 11. Corrosion potential Ecorr after $144 \mathrm{~h}$ exposure in the test solution.

All corrosion parameters are listed in Table 4.

Considering the measured values of corrosion rate, laser power $190 \mathrm{~W}$ can be recommended for implant sintering. However, for determining the suitability of production technology parameters, it is necessary to consider all properties of the material.

With respect to acceptance of the material by the human body, requirements for the surface roughness of the implants can vary. Therefore, experiments aimed at surface morphology modification by blasting were carried out. There were used two types of abrasives of different material and shape and three values of air pressure for blasting. The values of the roughness parameters measured on the material as-made and on materials blasted at different air pressures are shown in Table 5. Change of surface character is clear from profiles and Abbot-Firestone curve, Figure 12.

The results of blasting with Zirblast showed that increasing the air pressure lead to decreasing of $R a$. This result can be attributed to the ratio of hardness of Ti6Al4V vs. Zirblast. When comparing the 
parameters $R z$ and $R t$ it was shown their gradual decrease. Surface roughness in horizontal direction was characterized by parameters $R S m$ and $R P c$. There was recorded increasing of $R S m$ parameter at all air pressures by more than $100 \%$, the value of the parameter $R P c$ analogically decreased.

Table 4. Corrosion parameters of investigated materials.

\begin{tabular}{|c|c|c|c|c|c|c|c|}
\hline $\begin{array}{c}\text { Laser } \\
\text { Power (W) }\end{array}$ & Treatment & $\begin{array}{c}\text { Immersion } \\
\text { Time (h) }\end{array}$ & $\begin{array}{l}\text { Ecorr (mV } \\
\text { vs. SCE) }\end{array}$ & $\begin{array}{l}\text { Icorr } \\
(\mu \mathrm{A})\end{array}$ & $\begin{array}{l}\text { Beta c } \\
(\mathrm{mV})\end{array}$ & $\begin{array}{l}\text { Beta a } \\
(\mathrm{mV})\end{array}$ & $\begin{array}{c}\text { Rcorr } \\
\text { (mmpy) }\end{array}$ \\
\hline \multirow{4}{*}{150} & \multirow{2}{*}{ sintered } & 0 & -288.8 & 0.31 & 141.1 & 115.3 & 0.02 \\
\hline & & 144 & -263.4 & 3.03 & 213.3 & 234.3 & 0.16 \\
\hline & \multirow{2}{*}{ annealed } & 0 & -265.3 & 0.55 & 220.1 & 324.4 & 0.03 \\
\hline & & 144 & -270.1 & 2.38 & 192.2 & 227.6 & 0.13 \\
\hline \multirow{4}{*}{170} & \multirow{2}{*}{ sintered } & 0 & -220.9 & 0.02 & 48.9 & 36.7 & 0.94 \\
\hline & & 144 & -260.9 & 4.20 & 215.1 & 231.5 & 0.23 \\
\hline & \multirow{2}{*}{ annealed } & 0 & -217.0 & 0.02 & 11.0 & 15.0 & 0.75 \\
\hline & & 144 & -256.7 & 4.14 & 197.2 & 284.9 & 0.23 \\
\hline \multirow{4}{*}{190} & \multirow{2}{*}{ sintered } & 0 & -337.8 & 0.56 & 253.5 & 70.6 & 0.03 \\
\hline & & 144 & -171.1 & 0.25 & 82.8 & 518.2 & 0.01 \\
\hline & \multirow[b]{2}{*}{ annealed } & 0 & -416.0 & 5.00 & 514.0 & 208.9 & 0.24 \\
\hline & & 144 & -270.9 & 0.74 & 117.6 & 299.7 & 0.04 \\
\hline
\end{tabular}
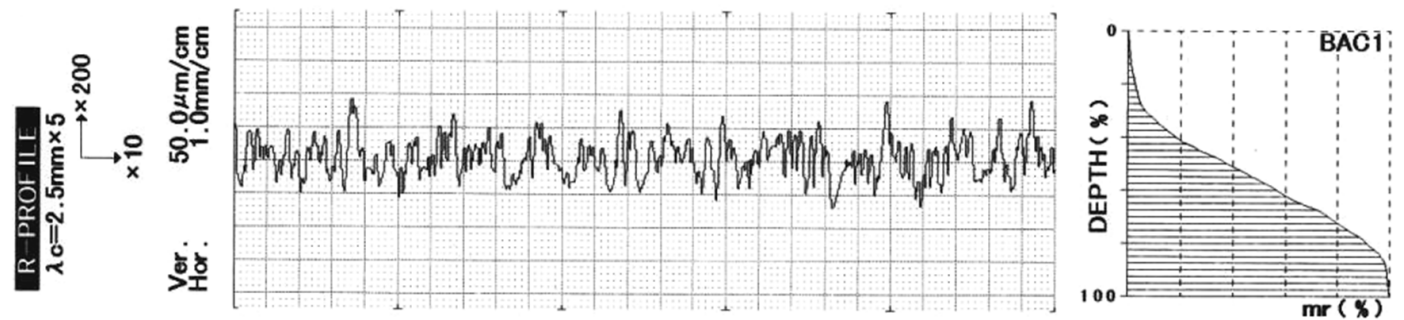

(a)
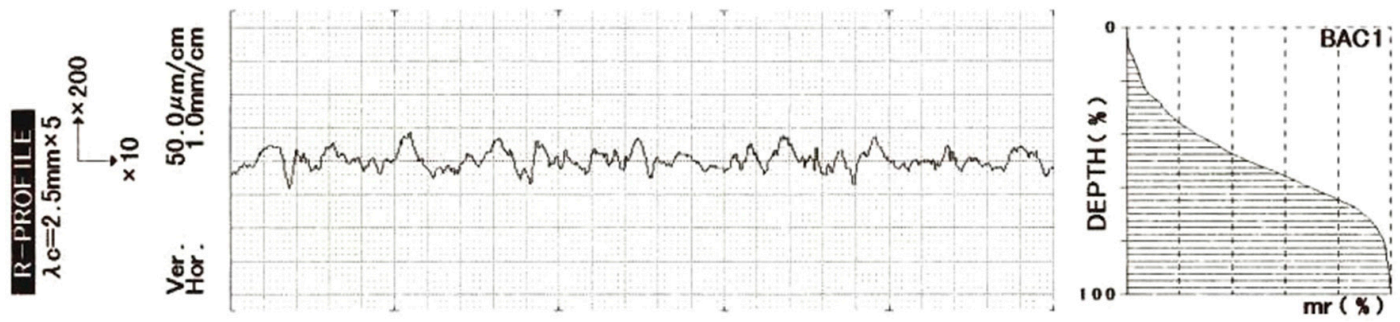

(b)
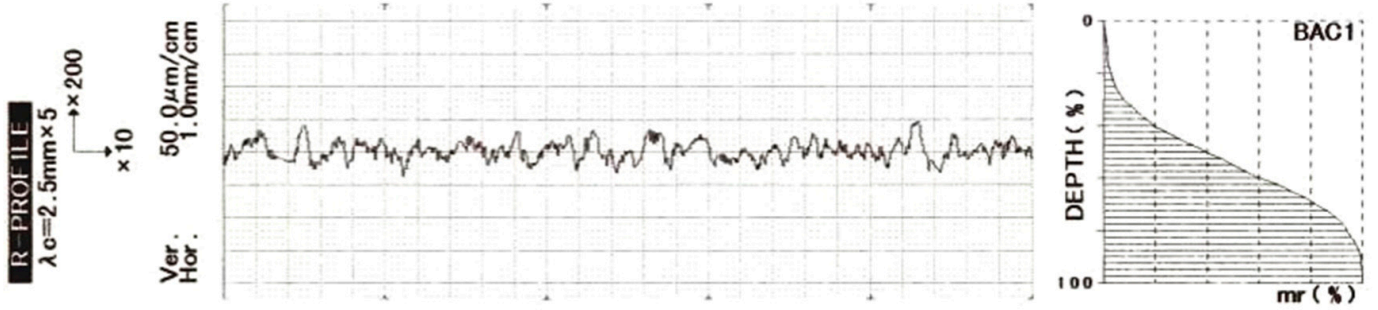

(c)

Figure 12. Profiles of materials as-made and blasted. (a) as-made; (b) Zirblast, 0.6 MPa; (c) White corundum, 0.6 MPa.

The group of sharp-edged blasting abrasives was represented by white corundum. The values of the parameters $R a, R z$, and $R t$ decreased with air pressure increasing, but reached higher values 
compared to surface blasted with Zirblast. The RSm value increased compared to as-made material by $85 \%$ and the value of RPc parameter decreased by $100 \%$. For both abrasives, despite their shape and material difference, a similar course of roughness parameters was recorded, but the values were higher for white corundum. Recommendation of appropriate blasting parameters and abrasives depends on the specific demands on the implant surface.

Table 5. Average values of the roughness parameters.

\begin{tabular}{|c|c|c|c|c|c|c|}
\hline \multirow{2}{*}{\multicolumn{2}{|c|}{ Surface }} & \multicolumn{5}{|c|}{ Roughness Parameters } \\
\hline & & $R a(\mu \mathrm{m})$ & $R z(\mu \mathrm{m})$ & $R \mathrm{t}(\mu \mathrm{m})$ & $R S m(\mu \mathrm{m})$ & $R P c\left(\mathrm{~cm}^{-1}\right)$ \\
\hline \multicolumn{2}{|c|}{ As-made } & 11.44 & 65.51 & 70.65 & 216.94 & 47.24 \\
\hline \multirow{3}{*}{$\begin{array}{l}\text { Blasted with } \\
\text { Zirblast }\end{array}$} & $0.2 \mathrm{MPa}$ & 6.24 & 37.96 & 42.23 & 458.87 & 22.65 \\
\hline & $0.4 \mathrm{MPa}$ & 5.74 & 35.91 & 41.11 & 476.37 & 22.08 \\
\hline & $0.6 \mathrm{MPa}$ & 4.93 & 29.35 & 32.59 & 469.09 & 21.93 \\
\hline \multirow{3}{*}{$\begin{array}{l}\text { Blasted with } \\
\text { white } \\
\text { corundum }\end{array}$} & $0.2 \mathrm{MPa}$ & 7.35 & 45.99 & 52.15 & 397.57 & 26.17 \\
\hline & $0.4 \mathrm{MPa}$ & 6.02 & 37.88 & 41.91 & 396.44 & 25.90 \\
\hline & $0.6 \mathrm{MPa}$ & 5.14 & 32.86 & 35.99 & 360.58 & 28.51 \\
\hline
\end{tabular}

Blasted surfaces were visualized using 3D maps and optical microscopy, Figure 13. 3D image of surfaces clearly showed the influence of blasting abrasives used to the final character of the surface. Surfaces blasted with spherical abrasive-Zirblast-are characterized by mutually intersecting indentations of spherical cap shape. Surfaces blasted with white corundum consist of large number of sharp notches.

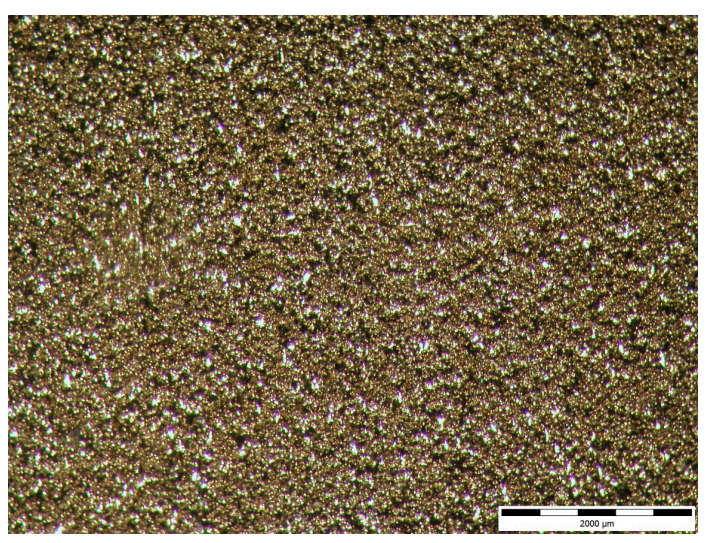

as-made

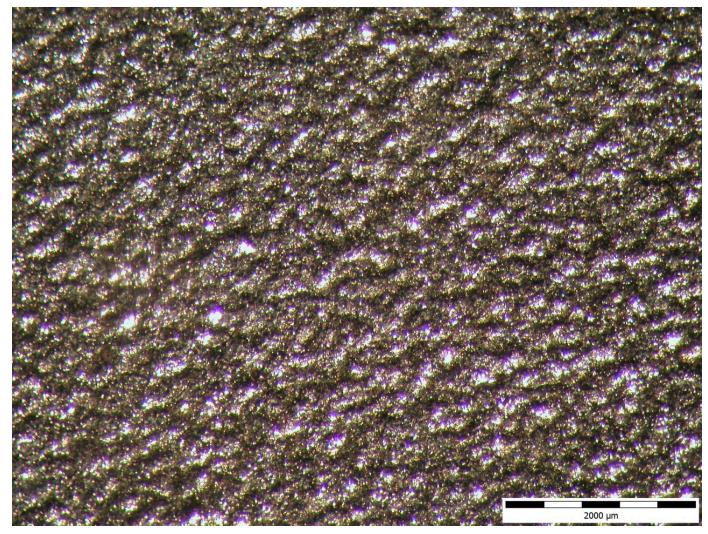

zirblast, $0.6 \mathrm{MPa}$
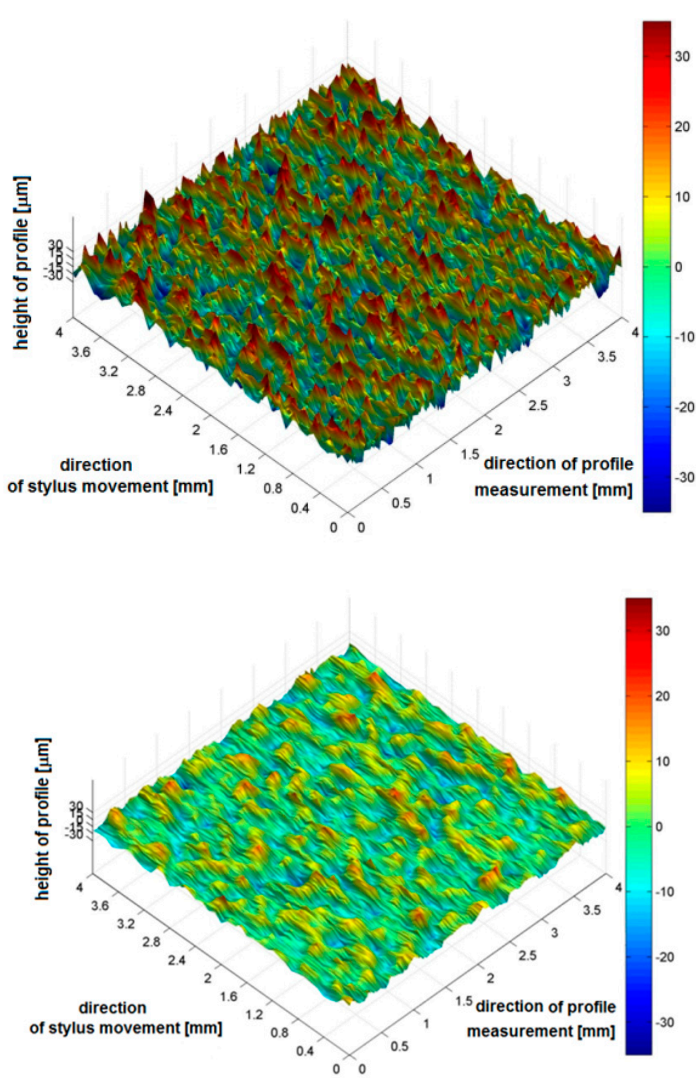

Figure 13. Cont. 

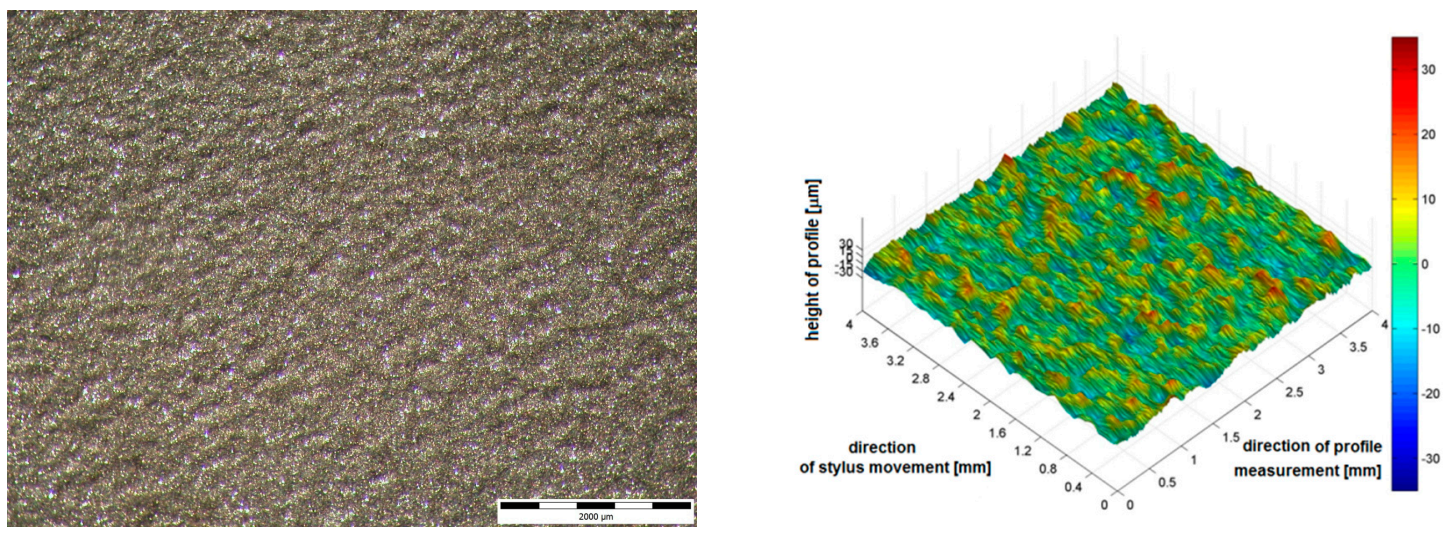

white corundum, $0.6 \mathrm{MPa}$

Figure 13. 3D maps and macro views on evaluated surfaces.

Surface volume $(V p)$ of evaluated surfaces is shown in Table 6 . The results showed that the $V p$ is higher in surfaces blasted with corundum. It confirms the assumption that the surface is more rugged when blasting with sharp-edged abrasive. These values correspond with results of surface roughness mentioned above. Increasing air pressure led to smoothing surface and lower surface volume.

Table 6. Surface volume of evaluated surfaces $\left(10^{8} \mu \mathrm{m}^{3}\right)$.

\begin{tabular}{llllc}
\hline As-Made & \multicolumn{2}{l}{ Blasted with Zirblast } & \multicolumn{2}{l}{ Blasted with White Corundum } \\
\hline \multirow{3}{*}{8.32} & $0.2 \mathrm{MPa}$ & 5.93 & $0.2 \mathrm{MPa}$ & 6.69 \\
& $0.4 \mathrm{MPa}$ & 4.38 & $0.4 \mathrm{MPa}$ & 4.93 \\
& $0.6 \mathrm{MPa}$ & 3.89 & $0.6 \mathrm{MPa}$ & 3.96 \\
\hline
\end{tabular}

In Table 7, we present the calculated $p$-values for the individual parameters measured on the samples which have been blasted with two blasting media. For the $R a, R z$, and $R t$ is a statistical difference in both blasting media. It means that the pressure effects the value of the parameter. For parameters $R S m$ and $R P c$ the sample blasted by Zirblast the difference is not statistically significant (pressure does not affect the value of the parameter) for the sample blasted white corundum difference is not statistically significant only for $\alpha=0.01$.

Table 7. $p$-Values for the individual parameter.

\begin{tabular}{ccc}
\hline Roughness Parameters & Zirblast & White Corundum \\
\hline$R \mathrm{a}$ & $6.36 \times 10^{-13} p<\alpha$ & $5.56 \times 10^{-27} p<\alpha$ \\
$R \mathrm{z}$ & $1.29 \times 10^{-16} p<\alpha$ & $1.21 \times 10^{-26} p<\alpha$ \\
$R \mathrm{t}$ & $1.86 \times 10^{-14} p<\alpha$ & $1.51 \times 10^{-24} p<\alpha$ \\
$R \mathrm{Sm}$ & $0.7255 p>\alpha$ & $0.0403 p<\alpha$ \\
$R \mathrm{Pc}$ & $0.7229 p>\alpha$ & $0.0323 p<\alpha$ \\
\hline
\end{tabular}

The average values of the Zirblast blasted and blasted by white aluminum oxide were compared using the $t$-test. The results of $p$-values at different pressure are depicted in the Table 8. At a working pressure of 2 bar, the difference is statistically significant. It means that the type of blasting media has an effect on the value of the parameter. At an operating pressure of 6 bars and 4, it is not statistically significant difference only for the Ra parameter (type of blasting media has no influence on the value of parameter). Therefore, the type of the blasting media has an influence on characteristics of profile roughness, in particular to its parameters. 
Table 8. $p$-Values at different pressure.

\begin{tabular}{cccc}
\hline Roughness Parameter & Pressure $\mathbf{2}$ bar & Pressure $\mathbf{4}$ bar & Pressure $\mathbf{6}$ bar \\
\hline$R \mathrm{a}$ & $2.78 \times 10^{-09} p<\alpha$ & $0.0818 p>\alpha$ & $0.1239 p>\alpha$ \\
$R \mathrm{z}$ & $1.84 \times 10^{-11} p<\alpha$ & $0.0354 p<\alpha$ & $1.68 \times 10^{-05} p<\alpha$ \\
$R \mathrm{t}$ & $2.09 \times 10^{-10} p<\alpha$ & $0.04948 p>\alpha$ & $0.0011 p<\alpha$ \\
$R \mathrm{Sm}$ & $0.0031 p<\alpha$ & $0.0003 p<\alpha$ & $1.07 \times 10^{-08} p<\alpha$ \\
$R \mathrm{PC}$ & $0.0011 p<\alpha$ & $0.0003 p<\alpha$ & $5.96 \times 10^{-09} p<\alpha$ \\
\hline
\end{tabular}

\section{Conclusions}

In order to determine the influence of laser power in Ti6Al4V powder sintering on mechanical properties and the corrosion behavior of sintered materials in the corrosive environment, we realized experimental works on a set of test samples sintered at three laser powers.

Mechanical properties were studied through hardness of materials. Material hardness showed different values with respect to the orientation of the measurement plane against sample building direction. Hardness of materials increased with laser power and values varying from 370 to $415 \mathrm{HV}$ $0.3 / 30$. After stress-relief annealing, the structure of materials became homogenized, pattern spacing dissolved, and hardness in both directions became stabilized at values of 350-370 HV 0.3/30.

Change in laser power led to a change in corrosion rate of materials in an environment of $3.5 \%$ $\mathrm{NaCl}$. At the highest laser power $(190 \mathrm{~W})$, corrosion rate significantly decreased, stress-relief annealing led to the stabilization of corrosion potential Ecorr.

Abrasive blasting of sintered materials, due to the substrate/abrasive hardness ratio, led to decrease of the surface roughness of materials with air pressure increasing. Blasting with Zirblast, due to the round shape of grains, led to a more significant decrease of roughness parameters compared with surfaces blasted with sharp-edged white corundum. Different shapes of abrasive caused characteristic surface morphology.

Surgeons, based on their clinical experiences, will know according to ethealon (samples with defined roughness) and palpation, which roughness is sufficient for which clinical case. Surface quality is selected according to the anatomical part of human body, function and mechanical properties of replaced tissue, and demand for osseointegration.

Acknowledgments: This work was supported by scientific grant agency of the Ministry of Education of the Slovak Republic VEGA No. 1/0600/13. The authors are grateful to the CEIT-KE, Ltd. in Košice, Slovak Republic for using of their laboratory facilities for experiments.

Author Contributions: Metallography analysis, hardness testing-J.B., A.G.; production and thermal treatment of test samples-R.H.; analysis of surface roughness—D.D.; statistical analysis of measured data-G.I.; measurement of corrosion rate-J.K.

Conflicts of Interest: The authors declare no conflict of interest.

\section{References}

1. Elias, C.N.; Lima, J.H.C.; Valiev, R.; Meyers, M.A. Biomedical applications of titanium and its alloys. JOM 2008, 60, 46-49. [CrossRef]

2. Mrázová, M.; Pilc, J. Research of titanium materials in medicine. Acta Tech. Corviniensis Bull. Eng. Fasc. 2012, 2, 85-86.

3. Niinomi, M.; Nakai, M. Titanium-based biomaterials for preventing stress shielding between implant devices and bone. Int. J. Biomater. 2011, 1-10. [CrossRef] [PubMed]

4. Schnitzer, M.; Lisý, M.; Hudák, R.; Živčák, J. Experimental measuring of the roughness of test samples made using DMLS technology from the Titanium alloy Ti-6Al-4V. In Proceedings of the SAMI 2015: IEEE 13th International Symposium on Applied Machine Intelligence and Informatics, Herlany, Slovakia, 22-24 January 2015; pp. 31-36.

5. Maya-Johnson, S.; López, D. Effect of the cooling rate in the corrosion behavior of a hot worked Ti-6Al-4V extra-low interstitial alloy. Mater. Des. 2014, 58, 175-181. [CrossRef] 
6. Pavón, J.; Jiménez-Piqué, E.; Anglada, M.; López-Esteban, S.; Saiz, E.; Tomsia, A.P. Stress-corrosion cracking by indentation techniques of a glass coating on Ti6Al4V for biomedical applications. J. Eur. Ceram. Soc. 2006, 26, 1159-1169. [CrossRef]

7. Bărbînţă, A.C.; Chelariu, R.; Crimu, C.I.; Istrate, B.; Nazarie, S.; Earar, K.; Munteanu, C. Metallographic characterization of a new biomedical titanium-based alloy for orthopedic applications. Bull. Transilv. Univ. Braşov Ser. I Eng. Sci. 2013, 6, 86-88.

8. Moravec, H.; Fojt, J.; Filip, V.; Joska, L. Modifikace povrchu titanu pro medicínské aplikace. Chem. Listy 2014, $108,40-45$.

9. Joshi, V.A. Titanium Alloys: An Atlas of Structures and Fracture Features; CRC Press: Boca Raton, FL, USA, 2006; p. 248.

10. Svoboda, E.; Bartošík, P.; Dvořáková, R.; Tran, Q.D. Influence of the measurement conditions on the surface roughness parameters. Hutn. Listy 2011, 64, 56-63.

11. Ali, S.H.R. Advanced nanomeasuring techniques for surface characterization, review article. Int. Sch. Res. Netw. ISRN Opt. 2012, 1-23. [CrossRef]

12. Draganovská, D.; Ižaríková, G.; Brezinová, J.; Guzanová, A. The study of parameters of surface roughness by the correlation analysis. Mater. Sci. Forum 2015, 818, 15-18. [CrossRef]

13. Brezinová, J.; Guzanová, A.; Draganovská, D. Abrasive Blast Cleaning and Its Application; Trans Tech Publications: Pfaffikon, Switzerland, 2015; p. 107.

14. Yadroitsev, I.; Krakhmalev, P.; Yadroitsava, I. Selective laser melting of Ti6Al4V alloy for biomedical applications: Temperature monitoring and microstructural evolution. J. Alloy. Compd. 2014, 583, 404-409. [CrossRef]

15. Song, B.; Dong, S.; Liao, H.; Coddet, C. Process parameter selection for selective laser melting of Ti6Al4V based on temperature distribution simulation and experimental sintering. Int. J. Adv. Manuf. Technol. 2012, 61, 967-974. [CrossRef]

16. Hudák, R.; Šarik, M.; Dadej, R.; Živčák, J.; Harachová, D. Material and thermal analysis of laser sintered products. Acta Mech. Automat. 2013, 7, 15-19.

17. Pyka, G.; Kerckhofs, G.; Papantoniou, I.; Speirs, M.; Schrooten, J.; Wevers, M. Surface roughness and morphology customization of additive manufactured open porous Ti6Al4V structures. Materials 2013, 6, 4737-4757. [CrossRef]

18. Ivanov, M.B.; Manokhin, S.S.; Kolobov, Y.R.; Nechayenko, D.A. Phase composition and microstructure of Ti-6Al-4V alloy after hydrogen-plastic working. Mater. Phys. Mech. 2010, 10, 62-71.

19. Qiu, C.; Adkins, N.J.E.; Attallah, M.M. Microstructure and tensile properties of selectively laser-melted and of HIPed laser-melted Ti-6Al-4V. Mater. Sci. Eng. A 2013, 578, 230-239. [CrossRef]

20. Wang, J.H.; Cheng, J.; Li, Y.X.; Bai, P.K. Influence of laser scan speed on density and mechanical properties of a Ti6Al4V part produced by means of selective Laser Melting (SLM). Lasers Eng. 2012, 23, 395-401.

21. Živčák, J.; Hudák, R.; Dadej, R. Výroba implantátov pomocou metódy Rapid Prototyping. Transf. Inov. 2013, 15, 24-30.

22. Bertol, L.S.; Júnior, W.K.; da Silva, F.P.; Aumund-Kopp, C. Medical design: Direct metal laser sintering of Ti-6Al-4V. Mater. Des. 2010, 31, 3982-3988. [CrossRef]

23. Ning, Y. Process Parameter Optimization for Direct Metal Laser Sintering (DMLS). Ph.D. Thesis, National University of Singapore, Singapore, 2005.

24. Custompart.net-Direct Metal Laser Sintering. Available online: http://www.custompartnet.com/wu/ direct-metal-laser-sintering (accessed on 10 April 2015).

(c) 2016 by the authors; licensee MDPI, Basel, Switzerland. This article is an open access article distributed under the terms and conditions of the Creative Commons Attribution (CC-BY) license (http://creativecommons.org/licenses/by/4.0/). 